\title{
Quinze anos da Residência Multiprofissional em Saúde da Família na Atenção Primária à Saúde: contribuições da Fiocruz
}

\author{
Fifteen years of Multiprofessional Residency in Family Health \\ at Primary Health Care: contributions from Fiocruz
}

Maria Alice Pessanha de Carvalho (https://orcid.org/0000-0001-8796-7545) ${ }^{1}$

Adriana Coser Gutiérrez (https://orcid.org/0000-0002-7305-5841) ${ }^{1}$
${ }^{1}$ Escola Nacional de Saúde Pública Sérgio Arouca, Fundação Oswaldo Cruz. R. Leopoldo Bulhões 1480 , Manguinhos. 21041-210 Rio de Janeiro RJ Brasil. alicep@ensp.fiocruz.br

\begin{abstract}
This article aims to present the experience of 15 years of the Family Health Residency Program of the Sérgio Arouca National School of Public Health (ENSP/Fiocruz) in the city of Rio de Janeiro-RJ, and seeks to identify the challenges and potentialities of the training process of preceptors facing the development of resident training programs. Presents one of its effects that resulted in the contribution with the development of a multiprofessional residency program in partnership with the Municipal Health Department of Campo Grande-MS. Seeks to identify the challenges and potentialities of preceptors training process in the face of the development of training programs for residents. From a theoretical point of view, it presents as cross-cutting questions, multiprofessionality, interprofessionality and the relationship between field and nucleus in the formation of residences in the health professional area. Concludes by pointing out the challenges contained in the practice of the preceptorship of the ENSP program and how they can be implemented in the project of Campo Grande, as well as a new trend for cooperative education institutions for the current model of expansion of residences with the unit offeror to the municipal health departments.
\end{abstract}

Key words Primary Health Care, Residence, Preceptorship, SUS
Resumo Este artigo tem por objetivo apresentar a experiência de 15 anos do Programa de Residência em Saúde da Família da Escola Nacional de Saúde Pública Sérgio Arouca (ENSP/Fiocruz) no município do Rio de Janeiro-RJ, e busca identificar os desafios e potencialidades do processo formativo de preceptores frente ao desenvolvimento de programas de formação de residentes. Apresenta um dos seus efeitos que resultou na contribuição com o desenvolvimento de um programa de residência multiprofissional em parceria com a Secretaria Municipal de Saúde do município de Campo Grande-MS. Busca identificar os desafios e potencialidades do processo formativo de preceptores frente ao desenvolvimento de programas de formação de residentes. Do ponto de vista teórico, apresenta como questões transversais a multiprofissionalidade, interprofissionalidade e a relação entre campo e núcleo na formação das residências em área profissional da saúde. Conclui por apontar os desafios contidos na prática da preceptoria do programa da ENSP e como podem ser implementados no projeto do município de Campo Grande, assim como uma nova tendência para as instituições de ensino de cooperação para o atual modelo de ampliação de residências tendo como unidade ofertante as secretarias municipais de saúde.

Palavras-chave Atenção Primária em Saúde, Residência, Preceptoria, SUS 


\section{Introdução}

A Atenção Primária em Saúde (APS) no Brasil é ainda um desafio para parte dos gestores no que se refere a expansão, financiamento, qualificação do processo de trabalho da gestão e atenção ${ }^{1-3}$. Assim como a necessidade de formar profissionais especialistas que saibam manejar as situações mais comuns do cotidiano de um serviço de APS, mas não em menor complexidade quando comparada a outros serviços de saúde. É sobre este aspecto da necessidade de formação especializada em APS que as residências em saúde se apresentam como importante recurso com vistas a superar essa desigual oferta formativa no país.

Face a essa compreensão a Fundação Oswaldo Cruz (Fiocruz), instituição de saúde pública dedicada ao ensino, pesquisa e assistência, priorizou a necessidade desse tipo de formação, constituindo desde 2005 umas das primeiras residências multiprofissionais em saúde da família por meio da cooperação da Escola Nacional de Saúde Pública (ENSP) e Secretaria Municipal de Saúde do Rio de Janeiro (SMS-RJ).

O Programa de Residência Multiprofissional em Saúde da Família (PRMSF)-ENSP/Fiocruz, já formou 313 egressos em sete profissões (enfermeiros, odontólogos, nutricionistas, assistentes sociais, psicólogos, farmacêuticos e profissionais de educação física) que ocupam funções estratégicas, tanto no campo assistencial como na gestão de serviços e sistemas de atenção primária nas diversas esferas de governo.

Ainda que em cenários de pouco investimento na ampliação de equipes da Estratégia Saúde da Família (ESF) o PRMSF se manteve presente com ofertas de turmas anuais. O pouco investimento na APS foi uma constante, exceto no período entre os anos de 2009 até 2017 onde o município do Rio de Janeiro ${ }^{3}$ realizou significativa expansão partindo de 3,5 para quase $70 \%$ de cobertura da ESF. O que acontece por meio da busca por mais parcerias para ampliação da demanda crescente de um modelo de atenção organizado a partir da APS. Na gestão seguinte acontece uma inflexão de investimentos e a cobertura retorna a cair e atinge patamares de $39,63 \%$ de cobertura da população carioca em junho de 2020.

Atualmente parte das residências em saúde na área da APS no Brasil sejam para médicos ou de perfil multiprofissional tem como instituição proponente as próprias SMS, justificada pelo incentivo de editais de fomento como o Pró-Residência do Ministério da Saúde (MS). No entanto, esse processo muitas vezes requer apoio técnico de instituições de ensino no que tange ao processo de gestão educacional.

O PRMSF-ENSP/Fiocruz surgiu como uma demanda vinda de um conjunto de trabalhadores da ESF no Município do Rio de Janeiro preocupados com a incipiente cobertura da APS, local e da frágil qualificação dos trabalhadores da rede naquele período que acompanha a sinergia do início de uma política de ampliação dos programas de residência em área profissional da saúde estimulada pela Secretaria de Gestão do trabalho e da Educação na Saúde (SGTES) possibilitaram a implantação dessa oferta educacional. Aliado a este contexto soma-se a perspectiva em contribuir para a gestão do cuidado da Atenção Básica no desenvolvimento da ESF em áreas urbanas e vulnerabilizadas ${ }^{4}$.

A formação objetivou atingir diferentes categorias profissionais com grau de qualificação em três áreas de competência: organização do processo de trabalho, cuidado à saúde na perspectiva da clínica ampliada (individual, coletivo e familiar) e formação sociopolítica, educação e saúde. Para o desenvolvimento dessas competências a proposta pedagógica tem como referência o construtivismo, problematização, construção compartilhada do conhecimento e a educação popular como referências metodológicas da práxis do processo de aprendizagem. Neste sentido, o projeto pedagógico da RMSF/ENSP ${ }^{5}$ buscou organizar a partir de algumas referências tais como:

- Currículo baseado em competências profissionais e trabalho interprofissional;

- Problematização da realidade produzindo ações de intervenções locais balizados pela educação popular;

- Integração formação e trabalho em um só processo de educação em serviço;

- Processo ensino-aprendizagem centrado no residente;

- Unidades de aprendizagens visando promover competências profissionais;

- Desenvolvimento do profissional reflexivo.

A formação da equipe multiprofissional e interprofissional envolveu a estratégia de agrupar os residentes em 5 equipes com categorias diferentes. Essa equipe de residentes integra uma equipe preceptora da Clínica da Família identificada como uma Clínica preceptora e permanece durante os dois anos de residência vinculado e este cenário de prática. Com a compreensão de que todos os trabalhadores que ali exercem suas funções são potenciais educadores e desenvolvem processos educacionais. Um preceptor de campo 
acompanha e coordena a formação no trabalho da ESF exercendo a função de preceptoria de campo e o acompanhamento do aprendizado específico para cada especialidade é exercido pelo preceptor de categoria, sendo muitos destes do Núcleo Ampliado da Saúde da Família (NAS$\mathrm{F}-\mathrm{AB})$. Os residentes participam de processos de supervisão de categoria que acontece mensalmente com um profissional considerado com alta competência para acompanhar um conjunto de profissionais residente de uma mesma categoria. Aqui se utiliza da concepção de campo e núcleo descritas por Campos ${ }^{6}$.

Um dos objetivos principais dessa formação passa pela compreensão e exercício da prática multiprofissional na práxis da interprofissionalidade. Na proposta da ENSP a multiprofissionalidade é mais do que juntar duas ou mais categorias nas cenas de intervenção ou formação. É "uma modalidade de trabalho coletivo que é constituído por meio da relação recíproca, de dupla mão, entre as múltiplas intervenções técnicas e a interação dos profissionais de diferentes áreas, configurando, através da comunicação" como aponta Peduzzi ${ }^{7}$. Segundo Ceccim $^{8}$ o conceito de Interprofissionalidade remete a intersecção de profissões, portanto, ao que é comum a mais de uma profissão; "Inter no interior de dois; no espaço comum de dois; ponto de cruzamento/ ligação/conexão". Já o conceito de profissionalidade diz respeito ao caráter do que é profissional, procedimento característico dos profissionais (sua maneira de ver e agir) e a sua competência profissional (conhecimento, habilidade e responsabilidade).

Ellery ${ }^{9}$, identifica três dimensões de desafios: a dimensão organizacional, na estruturação de uma rede de saúde escola, a coletiva, na organização dos profissionais como grupo de trabalho, e na dimensão subjetiva, onde os aprendentes possam se identificar com o modelo, saber lidar com as frustrações e promover afetividades no trabalho em ato. Para a autora esses são desafios para construção de um aprendizado que as instituições formadoras deverão enfrentar para desenvolver a prática interprofissional. A formação interprofissional possibilita a produção de encontros multiprofissionais e a realização de ações que podem ser exercidas por todos os trabalhadores de saúde em uma prática compartilhada e comum a todos. Muitas vezes realizam práticas e intervenções comuns ou mesmo de sua categoria incorporando saberes de outros núcleos profissionais em uma franca articulação entre campo e núcleo de saberes ${ }^{9}$.
Na compreensão da coordenação do RMSF/ ENSP para ocorrer inter-profissionalidade é preciso acontecer uma inter-relação e inter-ação em dinâmicas de construção compartilhada do conhecimento, saberes e prática desenvolvidos em relações de interação, cooperação e de produção de autonomia ${ }^{10}$. Perceber o alargamento do campo comum de conhecimentos e o "borramento" entre as fronteiras de cada profissão é a identificação de uma formação que compartilha a prática clínica ampliando seu escopo de ação, mas também a capacidade reflexiva de seus residentes nos momentos de interação e cooperação.

Na contramão da difícil realidade de muitos programas, o PRMSF reconheceu a necessidade de qualificar seus preceptores desde a primeira oferta, tendo como objetivo a formação pedagógica dos trabalhadores da rede de saúde nas unidades de saúde que se configuraria cenários de práticas. Identificando que a rede nem sempre contempla condições para assumirem, além das atividades de cuidado ao usuário, a formação de novos trabalhadores residentes. A presença das residências, nesses serviços possibilitou ampliar a qualificação da rede e aumentar a possibilidade do SUS exercer esse papel formador. Além do que provoca nos trabalhadores a necessidade de se qualificar como efeito de multiplicador. Vários preceptores buscaram realizar cursos de especialização ou em programas de stricto sensu (mestrado e doutorado), possibilitando, deste modo, a incorporação de novas estratégias tanto pedagógicas quanto assistenciais com vistas a produzir processos de intervenções nas práticas, nas pesquisas e nas ações de cuidado provocadas pela atuação dos residentes na rede.

É sobre essa articulação entre gestão municipal e a Fiocruz ao longo desses 15 anos na gestão do PRMSF que no final do ano de 2019 o município de Campo Grande identificou a necessidade de expansão e qualificação da sua rede APS e buscou estabelecer parceria através de uma cooperação técnica com a Fiocruz e o MS. O que resultou na elaboração de uma iniciativa com esta finalidade denominada Laboratório de Inovação de Atenção Primária em Saúde (LABINOVAAPS) ${ }^{11}$, sendo coordenada por um servidor com vivência anterior de ex-gestor da SMS-RJ no período de maior crescimento da cobertura da APS. Vivência esta que possibilitou compreender a necessidade de inclusão dentro do eixo formação a proposta de formação em residência em medicina de família e comunidade e multiprofissional na ESF. Essa iniciativa visou apoio técnico para os quesitos: desenvolvimento do projeto pedagó- 
gico; construção programática; construção das ferramentas pedagógicas; desenvolvimento do processo seletivo de residentes e preceptores e processo de formação de preceptores.

Com isso algumas áreas da Fiocruz foram mobilizadas para esse apoio como a direção do escritório da Fiocruz Mato Grosso do Sul, a coordenação geral de residências vinculada a Vice -Presidência de Educação, Informação e Comunicação (VPEIC) e particularmente a gestão da RMSF/ENSP dada a sua trajetória de experiência em parte aqui já apresentada. Importante destacar que até o ano de 2019 a Fiocruz tinha a tradição de ser exclusivamente unidade ofertante de seus próprios programas de residências, tendo esse cenário modificado a partir dessa cooperação, que talvez aponte para uma nova tendência das novas ofertas educacionais.

Este artigo tem como objetivo central apresentar a experiência de 15 anos do PRMSF/ENSP, apontar e analisar os desafios contidos na prática da preceptoria. Como consequência dessa experiência apresentar as potencialidades da parceria com um novo programa do município de Campo Grande com ênfase na formação de preceptores.

\section{Metodologia}

A proposta se caracteriza como um relato de experiência de um programa de residência multiprofissional da ENSP que existe há quinze anos no munícipio do Rio de Janeiro sob o compromisso de contribuir com a qualificação da APS em uma perspectiva situacional e o desenvolvimento de um novo programa no município de Campo Grande. Essa experiência possibilitou um exercício de implicação do observador em relação ao objeto e seu entorno e como uma proposta de projeto aplicação.

Este trabalho se caracteriza como abordagem qualitativa descritiva por se preocupar com um nível da realidade que não pode ser quantificada. No entanto, interage com dados quantitativos compreendendo que eles possam estabelecer complementariedade e não dicotomia ${ }^{12}$ valendose da análise documental associada à observação participante, pois se entende que são técnicas que se complementam em relação aos fenômenos estudados. A análise documental favorece a observação do processo de evolução do contexto em análise: projetos, indivíduos, grupos, conceitos, conhecimentos, comportamentos, práticas, entre outros $^{13}$. Nesta perspectiva metodológica foram utilizados como fonte os documentos de cons- trução curricular, regimento, projeto pedagógico, currículo do curso de formação de preceptores dos dois programas, atas da Coremu, livros, artigos de revistas indexadas relativas ao tema, sites públicos e registros escritos.

O público em tela foram os atores do processo de formação e os 44 preceptores do novo PRMSF Campo Grande em que as análises produzidas não tiveram a intenção de esgotar o tema, mas sim de fomentar o olhar crítico e reflexivo sobre a formação dos preceptores na qualificação dos residentes.

\section{Contexto de realização dos programas}

Campo Grande é um município de grande porte e a capital do estado do Mato Grosso do Sul. Segundo o Censo IBGE (2010), possui 786.979 habitantes com estimativa de 895.982 habitantes para 2019. Do ponto de vista da raça, $50 \%$ da população se autodeclaram brancos, $47 \%$ pardos e pretos, $0,7 \%$ indígenas e $1,7 \%$ amarelos. O Índice de Desenvolvimento Humano Municipal de 0,784 é considerado alto pela classificação do PNUD 2014. A Secretaria Municipal de Saúde (SESAU) possui uma rede de atenção básica que conta com 16 Unidades Básicas de Saúde (UBS), 53 Unidades Básicas de Saúde da Família e 12 equipes ENASF. Os serviços de saúde estão estruturados em gestão plena do sistema em todos os níveis de atenção: primária, secundária e terciária ${ }^{14}$.

Os Gráficos 1 e 2 apresentam os dois municípios em momentos bem distintos no sentido da cobertura tanto da ESF quanto da Atenção Básica.

É possível identificar que as duas cidades vivem contextos distintos quando relacionada a cobertura na APS. O Rio de janeiro que apresentava 62,68\% de cobertura de ESF em 2017 declinou para $39,63 \%$ em 2020 , ou seja, uma perda de $23,05 \%$ de cobertura. Enquanto em Campo Grande acontece o inverso, com crescimento de $24,39 \%$, passando de $37,99 \%$ em 2017 para $62,38 \%$ em 2020. O que permite que o município de Campo Grande oportunize capacidade de desenvolver inovações no campo da APS, incluso a possibilidade de expansão de cenários formativos para a região do Centro-Oeste ${ }^{15}$.

\section{O desafio do SUS-Escola}

Em recente artigo de opinião à Revista Consultor Jurídico a advogada e professora da Unicamp Lenir Santos ${ }^{3}$ afirma que o subfinan- 


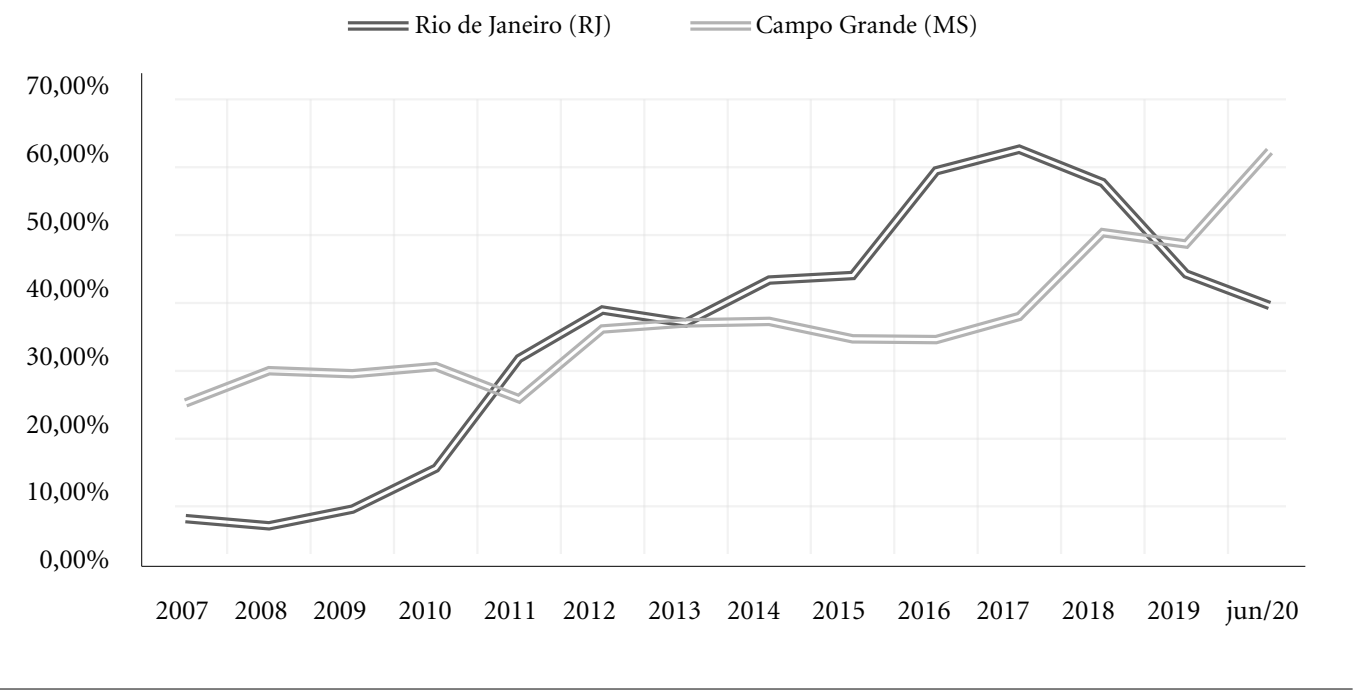

Gráfico 1. Cobertura Estratégia Saúde da Família no município do Rio de Janeiro -RJ e Campo Grande -MS período entre 2007-2020.

Fonte: MS/SAPS/Departamento de Saúde da Família (DESF) Unidades Geográficas: Brasil (https://egestorab.saude.gov.br/paginas/ acessoPublico/relatorios/relHistoricoCoberturaAB.xhtml, acesso em 19/08/2020).

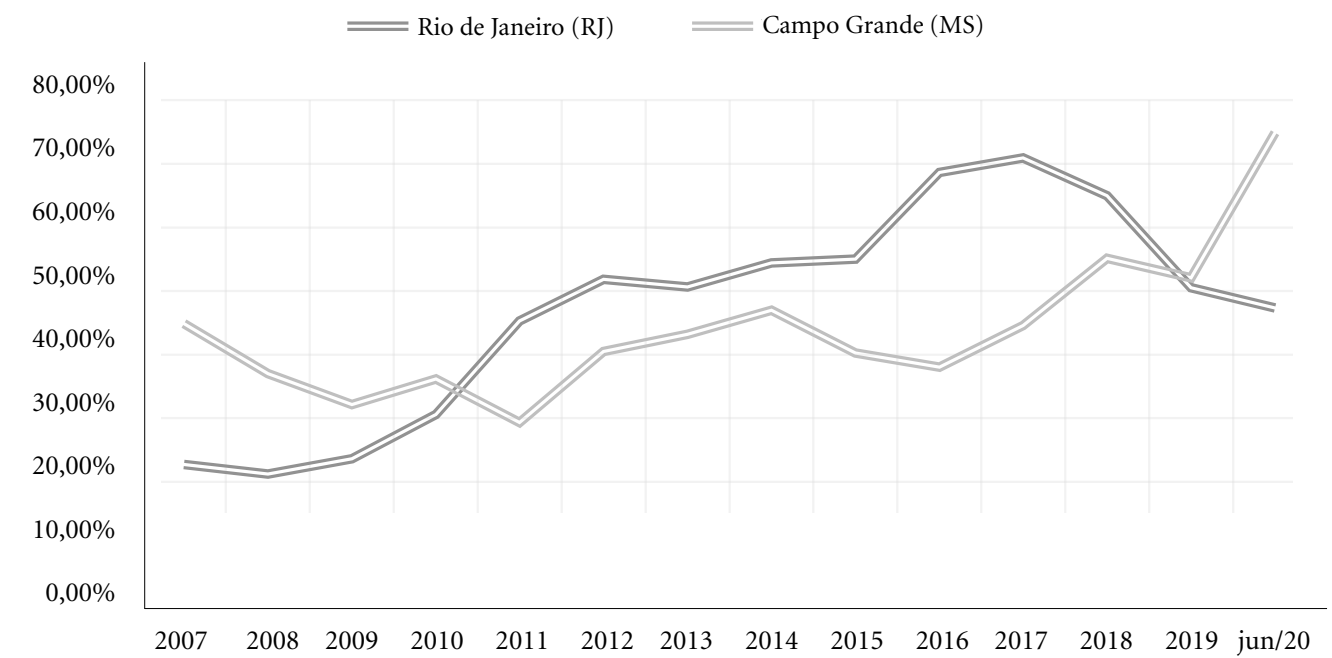

Gráfico 2. Cobertura Atenção Básica no municipio do Rio de Janeiro -RJ e Campo Grande -MS periodo entre 2007-2020.

Fonte: MS/SAPS/Departamento de Saúde da Família (DESF) Unidades Geográficas: Brasil (https:/egestorab.saude.gov.br/paginas/ acessoPublico/relatorios/relHistoricoCoberturaAB.xhtml, acesso em 19/08/2020). 
ciamento da saúde já havia atingido patamares elevados nos últimos dez anos com apenas $\mathrm{R} \$$ 3,60 per capita/dia. Para ela esses valores já não sustentavam o sistema de saúde público brasileiro. Ficando pior com a Ementa Constitucional no 95 , de 15 de dezembro de 2016, chamada de ementa do teto dos gastos porque congela os recursos da saúde e da educação por 20 anos. Para ela, esse processo pode instituir uma disputa predatória pelo orçamento federal entre os entes municipais e estaduais. A mesma autora não vê problemas no arcabouço jurídico do SUS, mas identifica que a formação de seus trabalhadores de saúde ainda é uma agenda a ser enfrentada embora prevista na Constituição Federal $(\mathrm{CF})^{16}$.

Ao longo dos 32 anos de existência do SUS a premissa de ordenamento da formação em saúde não foi consolidada em sua plenitude. Este, não definiu uma relação direta entre o conjunto de diretrizes para a diplomação desses profissionais e a rede pública de saúde. Articular cenários de formação e espaços de trabalho tem sido tanto para o Ministério da Educação (MEC) quanto para o Ministério da Saúde (MS) uma busca constante.

As Diretrizes Curriculares Nacionais (DCN $)^{17}$ deveriam funcionar como parâmetros de mudanças para formar profissionais para um novo modelo de saúde. Algumas propostas de modificações são direcionadas à esse marco tais como: formação por competências profissionais, deslocar o foco da doença para a saúde, equilibrar o cuidado individual e o coletivo, alargar o trabalho em equipe multiprofissional, desenvolver a educação permanente no contexto de trabalho e como estratégia pedagógica, metodologias baseadas na resolução de problemas e consubstanciadas em evidencia científica ${ }^{17}$ como estruturantes do projeto pedagógico.

O sistema formador tem se mostrado insuficiente em qualificar para a APS, tanto no nível médio quanto no técnico especializado. Em que pese algumas iniciativas promovidas pela SGTES/ MS desde 2005 como a Política de Educação Permanente, Política de Educação Popular e saúde e programas como VER-SUS, Promed, Pro-Saúde, Pet, Provab, Mais Médicos, GraduaSus, Prof-saúde $\mathrm{e} o$ incentivo às residências ${ }^{18}$.

As residências multiprofissionais em saúde têm se ocupado de parte desse desafio de qualificar a rede na perspectiva da educação permanente desde 2005. Quando da publicação da Lei $\mathrm{n}^{\circ} 11.129$, de 30 de junho de 2005 que institui o pró-jovem e cria as residências em área profissional da saúde, excetuada a área médica ${ }^{19}$.
Diante do exposto, podem ser elencados três grandes desafios que o sistema formador tem enfrentado e que necessita mobilizar ações:

1- Pensar processos que articulem trabalho e formação sem que um anteceda o outro. Necessita desenvolver processos pedagógicos que valorizem os diferentes saberes construídos nesta relação interprofissional e promover a valorização do saber na prática dos serviços de saúde. Reconhecer que no trabalho de uma equipe se desenvolvem conhecimentos e ações compartilhadas na construção diária da atenção à saúde.

2- Perceber atos educativos na vida, nas experiências com a saúde e a doença, nos casos e nas situações dos problemas reais em que as reflexões sobre as situações vividas possam contribuir para uma aprendizagem significativa. Aprendizagem que faça sentido ao aprendente e possibilite que os novos conhecimentos sejam ancorados nos conhecimentos prévios e relacionados às situações da vida real. Para tanto, necessita da articulação dos conhecimentos científicos com os conhecimentos do senso comum, do reconhecimento dos saberes circulantes na experiência dos atores.

3- Pensar a formação para desenvolver processos pedagógicos promotores de cuidados para com a vida do planeta, da cidade, do bairro, do território, do coletivo, de si e do outro. Esta formação necessita desenvolver a perspectiva da humanização da atenção, a produção de atos cuidadores, de responsabilização e implicação com as necessidades de quem se cuida, na produção de atitudes cuidadoras, que se envolvam em projetos individuais e coletivos na busca pela combinação trabalho com cuidado.

\section{Desafio do marco legal das residências}

As Residências em Área Profissional da Saúde objetivam a qualificação de jovens profissionais para inserção no SUS por meio da; cooperação intersetorial - responsabilidade conjunta dos setores da educação e saúde; regime de dedicação exclusiva; estratégias para o provimento e a fixação de profissionais em programas, projetos, ações e atividades e em regiões prioritárias para o SUS.

Por muitos anos a formação de residências área profissional da saúde (multiprofissional e uni profissionais) titulavam seus egressos como um curso de pós-graduação lato sensu equivalente a 360 horas, chamados de "Especialização nos moldes da residência". No entanto, os programas de residência em área profissional da saúde desenvolviam e desenvolvem seus currículos em 
uma carga horaria de 5.760 horas compreendidas em 60 horas semanais.

A Comissão Nacional de Residência Multiprofissional em Saúde (CNRMS) foi regulamentada pela Portaria Interministerial no 45 , de 15 de janeiro de 2007 depois substituída pela Portaria Interministerial MEC/MS No 1.077, de 12 de novembro de $2009^{20}$. Somente mais de dez anos depois a CNRMS publicou a resolução no 7 , de 13 de novembro de $2014^{21}$ que possibilitou a validação dos certificados de conclusão como Residência.

A SGTES-MS no ano de 2005, apoiou 22 Residências por acreditar na potencialidade pedagógica e política das Residências na redefinição do modelo tecno-assistencial do SUS. Hoje o MEC e o MS financiam juntos cerca de mais de 2.200 programas de residências em área profissional da saúde (SGTES/MS e SESu/MEC - 2019).

A partir de uma busca de informações no MEC foi possível identificar que no ano de 2019 as residências já contavam com um total de 2.239, sendo 1.118 multiprofissionais e 1.093 uniprofissionais. As informações apontam que dentre esses 230 programas não possuíam vínculo com instituição formadora. Na Figura 1 foram excluídos 215 programas por falta de informação tanto da cidade quanto do estado. O sistema SINAR/ MEC se mostrou de difícil acesso e insuficiente na apresentação das informações consolidadas o que impossibilitou produzir novas análises ${ }^{22}$. Mas é importante identificar o crescimento dos programas sem vínculo com as instituições de ensino e capazes de se constituírem como instituição proponente de programas de residência, sendo em boa parte deles ligados as secretarias de saúde e ou escolas de saúde públicas.

O projeto LABINOVAAPS visa ampliar a oferta de programas no centro oeste e o papel da Fiocruz neste processo de democratização da oferta de residências multiprofissionais. Para pensar uma rede de formação que objetive contribuir para a transformação e o aprimoramento da organização do trabalho em saúde e que integre os trabalhadores em saúde como sujeitos de conhecimento é necessário refletir como se constitui o preceptor.

\section{Preceptoria e funções}

Para esta formação o preceptor é compreendido como professor, orientador, facilitador e condutor do processo de aprendizagem; cabe a ele a responsabilidade de gerar hipóteses, estimular a reflexão crítica e a orientação das atividades que articulem a formação e o exercício do trabalho. Entende-se que, a formação humana é intencional e não se esgota na ação de um sujeito sobre o outro, sequer no ato de ensinar, já que ninguém - por mais preparado que esteja - é capaz de educar o outro, de supri-lo daquilo que lhe falta ou daquilo que precisa para a sua plena formação.

A Resolução $n^{\circ} 2$ da CNRMS, de 13 de abril de $2012^{23}$ apresenta que a função de preceptor se caracteriza por supervisão direta das atividades práticas realizadas pelos residentes nos serviços de saúde onde se desenvolve o programa, exercida por profissional vinculado à instituição formadora ou executora, com formação mínima de especialista. O preceptor deverá, necessariamente, ser da mesma área profissional do residente sob sua supervisão, estando presente no cenário de prática.

A supervisão de preceptor de mesma área profissional não se aplica a programas, áreas de concentração ou estágios voltados às atividades que podem ser desempenhadas por quaisquer profissionais da saúde habilitados na área de atuação específica, como por exemplo: gestão, saúde do trabalhador, vigilância epidemiológica, ambiental ou sanitária, entre outras.

Nessa prática docente demanda-se o enfrentamento e resoluções de desafios inerentes ao relacionamento humano, subjetividades, dinâmicas territoriais, gerenciamento, organização dos serviços, formação de cada categoria profissional, os processos avaliativos, a educação permanente e o domínio de outros conteúdos e prática assistenciais que coexistem como eixos orientadores dessa ação docente.

\section{Resultados}

Como já mencionado anteriormente, a SESAU além da cooperação já estabelecida com as universidades locais para qualificação de seus trabalhadores, resolveu também ampliar a parceria para a residência com a Fiocruz Mato Grosso do Sul para além da já expertise reconhecida com ofertas em pós-graduação strictu sensu, cursos de especializações e cursos livres de qualificação profissional incluso na modalidade a distância.

Importante destacar que a unidade ofertante, credenciada pelo MEC é a SESAU, que identificou a necessidade de formar uma equipe responsável pelo desenvolvimento do novo programa dado ao volume de vagas (77) e o tempo restrito de implantação articulado as demais iniciativas de qualificação da APS no município. Deste 


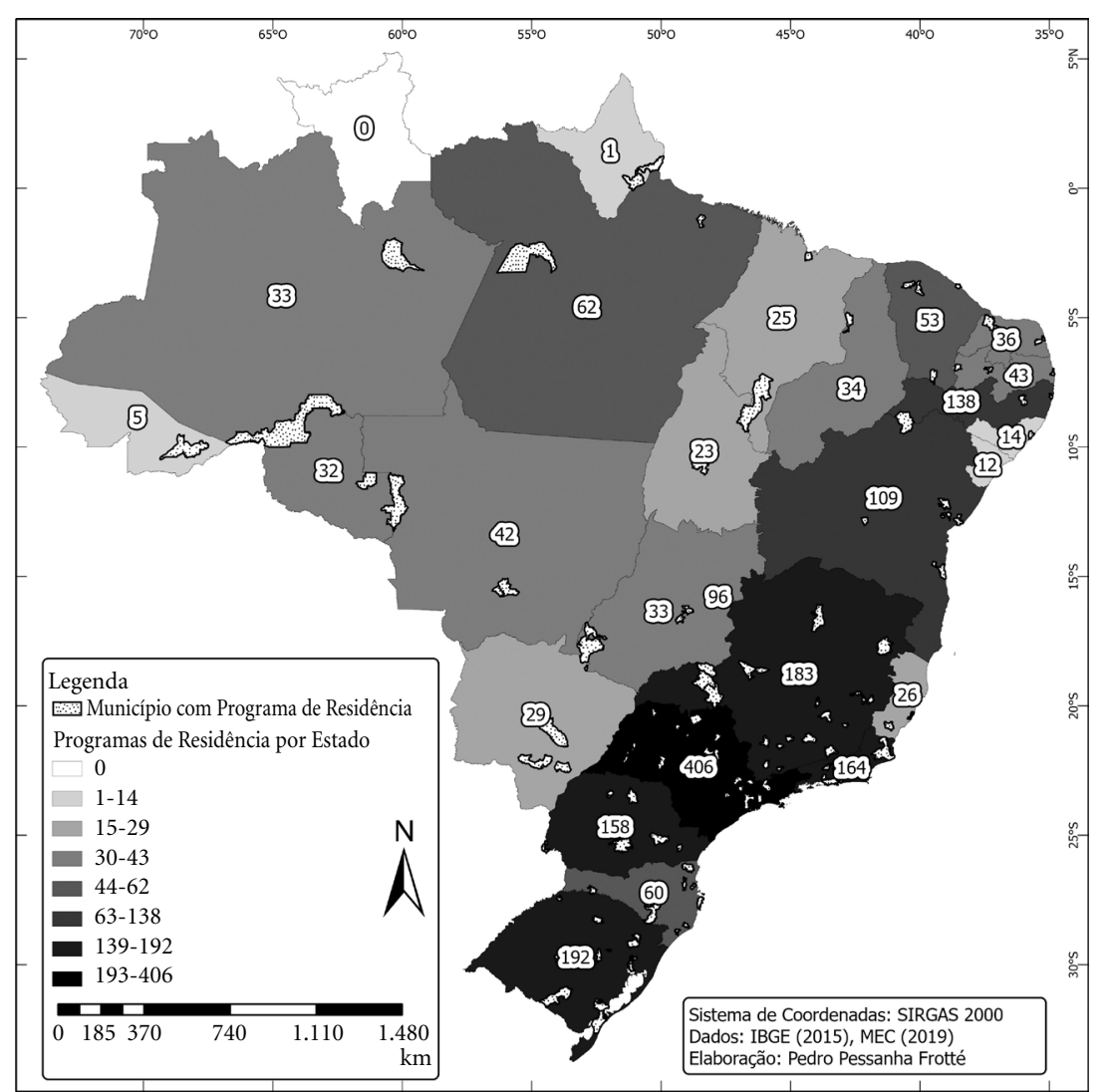

Figura 1. Distribuição dos programas de Residência em Área Profissional da Saúde (multiprofissional e uni profissional) nos Estados do país, Brasil, 2019.

Fonte: IBGE (2015) e MEC (2019).

modo a equipe gestora ficou a cargo de: Coordenação geral do programa de residência - 1 técnica indicada pela coordenação do LABINOVAAPS apoiada por 2 técnicos indicados pela SESAU; Coordenação pedagógica - 3 técnicas da Fiocruz, sendo 1 da Fiocruz Mato Grosso do Sul e mais 2 da Fiocruz do Rio de Janeiro; Apoiadores temáticos - 3 técnicos consultores com experiência prévia na SMS-RJ; Preceptores - profissionais das equipes de saúde da família da SESAU.

Sobre o apoio ao processo de formação de preceptores, é necessário recordar o que foi a etapa sobre o processo seletivo dos mesmos. Estes foram, inicialmente, submetidos a uma seleção de currículo e entrevistas coordenada por essa equipe gestora em que objetivo principal estava na identificação da disponibilidade do candidato para compor um perfil de referência técnica articulando as funções de núcleo e campo de competências, trabalho em equipe e ser educador o que implicava estudar e aprender com o outro.
Muitos foram os trabalhadores que se candidataram a este processo seletivo e o que se pode afirmar é que selecionar preceptores deste modo não é algo comum na maior parte dos programas, uma vez que esta função de preceptor acaba sendo atribuída a indicação do gestor ou ainda a aqueles profissionais que estão no turno do serviço em que há um residente em atividade prática.

Um outro aspecto interessante foi a proporção de 2 preceptores para 1 residente, assim como a remuneração no mesmo valor da bolsa do residente, o que certamente favorece uma dedicação diferenciada. Observa-se que isso só foi possível pelo financiamento do projeto LABINOVAAPS como apoio do MS, que seguiu o modelo já experimentado no município do RJ.

Para o conjunto de preceptores foi ofertado um curso introdutório de formação de preceptores com duração de 40h, realizado na Fiocruz do Rio de Janeiro sob a coordenação pedagógica do programa da ENSP. Esta formação priorizou 
às três dimensões: pedagógica, técnica e ética/ atitudinal. $\mathrm{O}$ uso de metodologias ativas utilizou temas como apresentação do projeto do LABINOVAAPS $^{11}$ e a conexão com a residência, marco regulatório, perfil de competência do preceptor, estratégias de construção de acolhimento aos residentes, discussão de casos, visita a rede de serviços da SMS-RJ dentre outros. Destaca-se que este processo foi construído a partir da experiência da RMSF/ENSP.

Com a chegada dos residentes aos cenários de prática, novos encontros foram agendados com os preceptores seguindo a perspectiva de educação permanente, temas como escuta do contexto local da estrutura das unidades e apoio da SESAU, as expectativas e planejamento das primeiras semanas de acolhida aos residentes. $\mathrm{O}$ interessante destes primeiros encontros foi também construir com este grupo a distinção da dupla função de preceptores e membros das equipes de saúde. Para a equipe da coordenação geral da residência a também distinção entre o desafio de serem gestores educacionais e não apoiadores da gestão da SMS.

Um aspecto interessante é reconhecer que os processos de formação dos preceptores não se deram exclusivamente nos momentos de encontros com a coordenação pedagógica. Aconteceram nos variados encontros também propostos pela coordenação geral do programa e na relação com os próprios residentes.

Com a chegada da pandemia COVID-19, os encontros passaram para a modalidade remota, com o destaque para a função de tutoria dos preceptores juntos aos residentes presencias, de oferta de atividades em Educação a Distância (EAD) para dar sequência a primeira parte do conteúdo programático. Em paralelo os encontros de educação permanente foram priorizados sempre temas trazidos pelo próprio grupo aliados as ofertas sempre articuladas com a necessidade da coordenação geral. A exemplo da construção de referenciais de avaliação dos residentes assim como aportes as dimensões de competência nucleares de cada preceptor, ou seja, uma formação que valorize a formação de campo, mas de núcleo também.

\section{Considerações finais}

É possível afirmar que alguns ganhos neste processo ainda em curso podem ser identificados, sendo o primeiro é que se mostra como tendência a ser melhor observada não somente para a Fiocruz esta iniciativa de cooperar com outras instituições do SUS, na perspectiva de não ser necessariamente a gestora proponente junto ao MEC, e sim criando novas possibilidade de cooperação em outros campos, no caso da gestão educacional, processo seletivo etc. E essa experiência sem dúvida, pode ser plenamente aplicável por outras instituições de ensino tal qual a Fiocruz com particular interesse em contribuir para a expansão e qualificação de residências em APS.

Como segundo aspecto podemos observar que a experiência acumulada na gestão educacional do PRMSF/ENSP se mostrou potente na facilitação da cooperação com um novo programa formativo. Principalmente neste momento das etapas iniciais no desenvolvimento do novo programa.

O terceiro aspecto é a aposta de se trabalhar com apoio técnico e financeiro o que possibilita investimentos na formação permanente dos preceptores, tanto do ponto de vista das atribuições como no aspecto organizacional o que facilita a contratualização, a motivação dos mesmos. Mas o desafio talvez esteja em como sustentar iniciativas semelhantes sem o apoio financeiro como neste caso para o pagamento de bolsas para os preceptores.

Destaca-se por fim que esta experiência de qualificação dos preceptores deve estar plenamente articulada com o projeto de gestão municipal de saúde, com vistas a finalidade maior que é reconhecer a formação como um recurso potente para a qualificação da APS, tendo como objetivo o cuidado pela não reprodução de um modelo exitoso, mas sim a customização de acordo a necessidade local.

\section{Colaboradores}

MAP Carvalho trabalhou na concepção, pesquisa, metodologia e redação final. AC Gutiérrez trabalhou na metodologia, análise e redação final. 


\section{Referências}

1. Carvalho M, Santos NR, Campos GWS. A construção do SUS e o planejamento da força de trabalho em saúde no Brasil: breve trajetória histórica. Saúde Debate 2013; 37(98):372-387.

2. Brasil. Ministério da Saúde (MS) [Internet]. [acessado 2020 ago 20]. Disponível em: http://www.saude.gov. br/sistema-unico-de-saude.

3. Santos L. SUS: reformar é mesmo preciso? [Internet]. [acessado 2020 ago 12]. Disponível em: https://www. conjur.com.br/2020-ago-12/lenir-santos-sus-reformar-mesmo-preciso?imprimir $=11 / 5$.

4. Soranz D, Pinto LF, Penna GO. Eixos e a Reforma dos Cuidados em Atenção Primária em Saúde (RCAPS) na cidade do Rio de Janeiro, Brasil. Cien Saude Colet 2016; 21(5):1327-1338.

5. Programa de Residência Multiprofissional em Saúde da Família (PRMSF). Escola Nacional de Saúde Pública Sérgio Arouca (ENSP). Fundação Oswaldo Cruz (Fiocruz). Projeto Politico Pedagógico do Programa de Residência Multiprofissional em Saúde da Família. Rio de Janeiro: ENSP/Fiocruz; 2007.

6. Campos GWS. Saúde pública e saúde coletiva: campo e núcleo de saberes e práticas. Cien Saude Colet 2000; 5(2):219-230.

7. Peduzzi M. Trabalho em equipe. In: Pereira IB, Lima JCF. Dicionário da educação profissional em saúde. $2^{\mathrm{a}}$ ed. rev. ampl. Rio de Janeiro: EPSJV; 2008.

8. Ceccim RB. Conexões e fronteiras da interprofissionalidade: forma e formação. Interface (Botucatu) 2018; 22:1739-1749.

9. Ellery AEL. Interprofissionalidade na estratégia saúde da família: condições de possibilidade para a integração de saberes e a colaboração interprofissional [tese]. Fortaleza: Universidade Federal do Ceará; 2012.

10. Minayo MCS, organizadora. Pesquisa Social. Teoria, método e criatividade. 18a ed. Petrópolis: Vozes: 2001.

11. Centro de Estudos Estratégicos (CEE). Laboratório de Inovação na Atenção à Saúde (INOVAAPS). Institucional [Internet]. [acessado 2020 ago 12]. Disponível em: http://labinovaapsfiocruz.com.br/portal/\#/institucional.

12. Carvalho MAP. Construção compartilhada do conhecimento: análise da produção de material educativo. In: Brasil. Ministério da Saúde (MS). Secretaria de Gestão Estratégica e Participativa. Caderno de Educação Popular e Saúde. Brasília: MS; 2007. p. 91-102.

13. Cellard AA. A pesquisa qualitativa: enfoques epistemológicos e metodológicos. Petrópolis: Vozes; 2008.

14. Brasil. Ministério da Saúde (MS). Secretaria de Gestão do Trabalho e da Educação na Saúde. Departamento de Gestão da Educação na Saúde. Residência Multiprofissional em saúde: experiências, avanços e desafios. Brasília: MS; 2006.

15. Brasil. Ministério da Saúde (MS). Secretaria de Atenção Primária à Saúde. Departamento de Saúde da Família. Unidades Geográficas: BRASIL [Internet]. [acessado 2020 ago 20]. Disponível em: https://egestorab.saude.gov.br/paginas/acessoPublico/relatorios/relHistoricoCoberturaAB.xtml.
16. Brasil. Emenda Constitucional no 95, de 15 de dezembro de 2016. Altera o Ato das Disposições Constitucionais Transitórias, para instituir o Novo Regime Fiscal, e dá outras providências. Diário Oficial da União 2016; 15 dez.

17. Brasil. Resolução CNE/CES no 4, de 7 de novembro de 2001. Institui Diretrizes Curriculares Nacionais do Curso de Graduação em Medicina. Diário Oficial da União 2001; 9 nov.

18. Moreira COF, Dias MSA. Diretrizes Curriculares na saúde e as mudanças nos modelos de saúde e de educação. ABCS Health Sciences 2015; 40(3):300-305.

19. Brasil. Lei no 11.129 , de 30 de junho de 2005. Institui o Programa Nacional de Inclusão de Jovens - ProJovem; cria o Conselho Nacional da Juventude - CNJ e a Secretaria Nacional de Juventude; altera as Leis $\mathrm{n}^{\circ} \mathrm{s}$ 10.683, de 28 de maio de 2003, e 10.429, de 24 de abril de 2002; e dá outras providências. Diário Oficial da União 2005; $1^{\circ}$ jul.

20. Brasil. Portaria Interministerial no 1.077 , de 12 de novembro de 2009. Dispõe sobre a Residência Multiprofissional em Saúde e a Residência em Área Profissional da Saúde, e institui o Programa Nacional de Bolsas para Residências Multiprofissionais e em Área Profissional da Saúde e a Comissão Nacional de Residência Multiprofissional em Saúde. Diário Oficial da União 2009; 13 nov.

21. Brasil. Resolução CNRMS n 7 , de 13 de novembro de 2014. Regulamenta os processos de avaliação, supervisão e regulação de programas de Residência em Área Profissional da Saúde. Diário Oficial da União 2014; 17 nov.

22. Brasil. Ministério da Educação (MEC). Sistema Nacional de Residências em Saúde - SINAR [Internet]. [acessado 2020 ago 12]. Disponível em: http://sinar. mec.gov.br/primeiro-acesso.

23. Brasil. Ministério da Educação (MEC). Resolução $n^{\circ}$ 2, de 13 de abril de 2012. Dispõe sobre as Diretrizes Gerais para os Programas de Residência Multiprofissional e em Profissional de Saúde. Diário Oficial da União 2012; 16 abr.

Artigo apresentado em 01/10/2020

Aprovado em 18/12/2020

Versão final apresentada em 20/12/2020

Editores-chefes: Maria Cecília de Souza Minayo, Romeu Gomes, Antônio Augusto Moura da Silva 